\title{
Brilliant Green Decorated Graphene Oxide for the Detection of Cucurbit[7]uril
}

\author{
Ramesh Prakash, Narayanan Selvapalam Govindaraj Usha, Karuppasamy Karpagalakshmi, \\ Lakshminarayanan Piramuthu
}

\begin{abstract}
Among the synthetic receptors, Cucurbiturils have gained much attention recent days due to their unique binding potential with variety of drugs and dyes. However, no facile detection method using $U V$-vis spectroscopy has been developed. Here, we have developed the brilliant green decorated graphene oxide (BGGO) for the detection of cucurbit[7]uril (CB[7]) with good selectivity and sensitivity. Thus, BGGO could able to detect the $\mathrm{CB}[7]$ and turn on the release of brilliant green quantitatively. Among the sensors for $\mathrm{CB}$ [7], $\mathrm{BGGO}$ is the low-cost and sensitive sensor for $\mathrm{CB}[7]$ with high selectivity
\end{abstract}

Keywords : $\mathrm{CB}[7]$ sensor, graphene oxide, Brilliant green, Cucurbituril.

\section{INTRODUCTION}

C ucurbiturils are the class of macrocycles, which have been expanded in many emerging areas of research, especially for the targeted dug delivery materials and for bottom up approach materials that include nanocapsules and dye removal materials. [1]. Macrocycles have been categorized based on the charges of the guests, which can get incorporated into the host molecules. More recently developed Pillarenes, crown ethers and cucurbiturils have the potential to interact with cationic guest molecules, while the other categories of host molecules such as cyclodextrins have the potential to interact with neutral and anionic guest molecules. However, the binding properties of cucurbituris are very unique and for that purpose they have gained much attention recent days [2]. Based on the structural features of cucurbiturils, they have been explored as portals of the cucurbiturils are built by the rim of carbonyls, while the hydrophobic cavities of cucurbiturils are having the potential to interact with the hydrophobic molecules [3], [4]. The basic building blocks of the cucurbiturils are made up of glycolurils and formaldehyde by the acid-catalyzed condensation, which provided the hydrophobic interior and hydrophilic exterior to attract the molecules of choice (guests) [5], [6]. The size variation of the

Revised Manuscript Received on July 22, 2019.

* Correspondence Author

Ramesh Prakash Center for Supramolecular Chemistry, IRC and Department of Chemistry, Kalasalingam Academy of Research and Education, Krishnankoil 626126, India.n.selvapalam@klu.ac.in

Narayanan Selvapalam Center for Supramolecular Chemistry, IRC and Department of Chemistry, Kalasalingam Academy of Research and Education, Krishnankoil 626126, India. n.selvapalam@klu.ac.in

Govindaraj Usha Center for Supramolecular Chemistry, IRC and Department of Chemistry, Kalasalingam Academy of Research and Education, Krishnankoil 626126, India. n.selvapalam@klu.ac.in cucurbiturils are very different from smaller to large as denoted by the number of glycolurils present in the core of the host molecules [7]. For example, Cucurbit[5] uril can be abbreviated as $\mathrm{CB}[5]$ and the available variations are denoted as $\mathrm{CB}[\mathrm{n}]$, where $\mathrm{n}=5-8,10,14$. Although a lots of structural variations have been explored within the $\mathrm{CB}[\mathrm{n}]$ host molecules, $\mathrm{CB}$ [7] has been attracted to scientific community for the reason of abundant solubility in water, through which many biological experiments have been carried out, especially drug delivery related studies and they also showed exceptional binding affinity in water with many biologically important molecules $[6,8]$. Due to the large cavity size nature of $\mathrm{CB}$ [7] and $\mathrm{CB}$ [8], they have explored applications such as drug carrier in biotechnological applications, biomolecule complexation studies, toxicity and taste masking studies and many other biorelated applications. Thus, $\mathrm{CB}$ [7] and $\mathrm{CB}[8]$ gained much attention in recent studies. Besides, $\mathrm{CB}[6]$ and $\mathrm{CB}$ [7] also contributed in areas of protein, peptides and amino acids complexation studies [9]. For example, CB [7] made complexation with biologically important molecule such as Insulin and selective complexation of a particular amino acids within the peptide molecules [10]. Among the various host molecules available in the supramolecular field, cucurbiturils could be an alternative to the encapsulation studies of oral and topical drug delivery forms, when compared with the applications that were carried out with cyclodextrins, [11]. Under the wrap of CB[7], molecules such as drugs attained stability and improved the solubility, because drug molecule get complexed with $\mathrm{CB}$ [7] to become a single entity [12]. A few important drugs that have been complexed with $\mathrm{CB}[7]$ and $\mathrm{CB}[8]$ are listed here. For example, an important cancer drug, cisplatin [13] and camptothecin [14], antileprosy drugs for the treatment of lepromatous leprosy such as clofazimine [15], fungicide such as fuberidazole [16], HIV-1 drug such as adefovir, and many other drugs such as bis(L-phenylalanine propyl)ester [17], ranitidine and fasudil, [18] have been examined. All these studies indicate the role of $\mathrm{CB}[\mathrm{n}]$ in the medicinal and material science areas and thus detection of $\mathrm{CB}[\mathrm{n}]$ should be important, because they could not be recognized or visualized by the UV and other staining agents, except Iodine, which also displayed very weak signals/spot under various environments.

Unlike the other organic molecules, identification and quantification $\mathrm{CB}[\mathrm{n}]$ or $\mathrm{CB}[7]$ is very challenging. Without the aid of maldi-tof and NMR, it would be very difficult to trace the quantity of $\mathrm{CB}[\mathrm{n}]$ by any other affordable techniques,

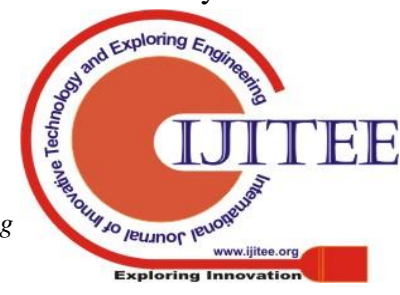


such as TLC and UV-vis spectroscopy, which are commonly employed by the organic chemist to trace the organic molecule qualitatively. Therefore, developing a facile visible dye based sensor would support the detection of CBs for in-vivo and in-vitro applications to detect the presence of CBs. Furthermore, visible dye based CB sensor would also support the synthesis of functionalized CBs, for which we require a facile sensor for the laboratory use. Recently, our research group have published a $\mathrm{CB}$ sensor based on a rhodamine B decorated copper nanoparticle by the method of fluorescence turn-on technique [19]. In a similar way, we have explored the utilization of graphene oxide as a core material, on which rhodamine B was bound non-covalently. This graphene oxide decorated rhodamine material could detect very selectively $\mathrm{CB}$ [7], among the various members of CB host family members [20]. However, it required quantification of $\mathrm{CB}[7]$ and that led to explore other inexpensive ways to quantify the $\mathrm{CBs}$, especially for the $\mathrm{CB}$ [7]. So, we decided to change the fluorescent dye that we used to decorate the graphene oxide by the non-fluorescent dye to explore the same hypothesis, which would require only visible spectrophotometer and such instruments are the most inexpensive one. Among the various dyes existing, we have selected brilliant green (BG), because it is an inexpensive dye with high intensive color, even at the lowest concentration [21]. Brilliant green is expected to get absorbed on graphene oxide by the non-covalent interactions through the $\pi-\pi$ interactions of the aromatic groups of dye with the graphene oxide [22, 23]. As expected, brilliant green decorated graphene oxide (BGGO) also successfully released the BG upon interaction with the $\mathrm{CBs}$, indicating that BGGO could be the choice of material for sensing the $\mathrm{CBs}$ in a more affordable way. Therefore, the sensor may provide a facile and affordable way for the determination of $\mathrm{CB}$ [7] by the usage of BGGO. Similar to cyclodextrins, $\mathrm{CB}$ [7] has been explored to make complexation with many of the pharmaceutically important drugs, which are expected to be available in the market in the next century and an affordable sensor would be useful for the pharma industry for the determination of $\mathrm{CB}$ [7]. Thus, our method of determination of $\mathrm{CB}[7]$ using BGGO would be an useful technique for the laboratories of pharma industry. Besides, during the synthesis and isolation of functionalized $\mathrm{CB}$ [7], it is hard to measure the presence of $\mathrm{CB}$ [7] in the water solution, because $\mathrm{CB}$ [7] does not possess any chromophoric groups on it. For this reason, BGGO would provide an opportunity to measure $\mathrm{CB}$ [7] in the solution very conveniently. Overall, the present sensing method of $\mathrm{CB}$ [7] would help the supramolecular chemists and the pharma industry in many ways in the future.

\section{RESULT AND DISCUSSION}

BGGO is the key material that has been prepared based on our previous work that we published by replacing the dye of rhodamine B by brilliant green [20]. The core material graphene oxide was prepared by the modified hummers work [20]. Here, we have mentioned briefly the procedure to understand the preparation method of BGGO. The core expensive fluorescence spectrophotometer for the method, which was also mentioned in detail in our previous

material graphene oxide was prepared from the commercial source of graphene by using the oxidants such as $\mathrm{KMnO}_{4}$ $\mathrm{NaNO}_{3}$ and hydrogen peroxide in water. The water soluble portion of graphene oxide was extracted and concentrated to obtain the water soluble graphene oxide. For example, $2 \mathrm{~g}$ of graphene was treated with $\mathrm{NaNO}_{3}$ in ice bath and subsequently digested with $90 \mathrm{~mL}$ sulfuric acid and stirred it for $4 \mathrm{~h}$, which peeled the graphite to single or multi layers graphene oxidative product, which is water soluble product. Afterwards, $12 \mathrm{~g}$ of $\mathrm{KMnO}_{4}$ was added to oxidize the peeled graphene oxide at temperature below $15{ }^{\circ} \mathrm{C}$ and it was further diluted with $184 \mathrm{~mL}$ of water and stirred further $2 \mathrm{~h}$ in ice bath and $2 \mathrm{~h}$ at $35^{\circ} \mathrm{C}$. It was later boiled at $98^{\circ} \mathrm{C}$ for $15 \mathrm{~min}$ and the solution become dark brown. To this, $40 \mathrm{~mL}$ of hydrogen peroxide and $400 \mathrm{~mL}$ water were added, which changed the solution to yellow. The product obtained was treated with 10 $\% \mathrm{HCl}$ and neutralized by multiple washing with DI water. The final product's volume was adjusted to $100 \mathrm{~mL}$ and retained this solution for further studies [20].

Brilliant green adhered to the graphene oxide and obtained the BGGO. In brief, $96 \mathrm{mg}$ of brilliant green $(1 \mathrm{mM})$ and $4 \mathrm{~mL}$ of graphene oxide were dissolved in $200 \mathrm{~mL}$ water. To that, $700 \mu \mathrm{L}$ of hydrazine hydrate $(30 \%)$ was added and stirred at room temperature for $12 \mathrm{~h}$ for the brilliant green to get adsorbed on graphene oxide. It was stored in dark for $72 \mathrm{~h}$ and the unbound brilliant green was removed by multiple water

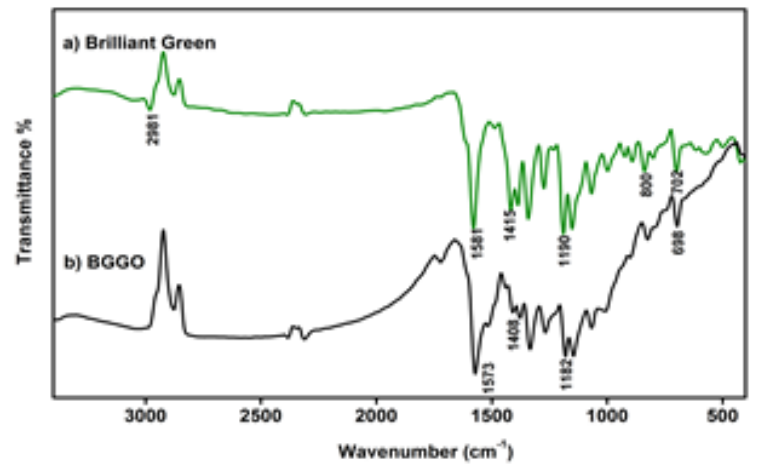

Fig 1. FTIR Spectrum of brilliant green decorated graphene oxide - BGGO

wash. Furthermore, it was treated with $1 \mathrm{M} \mathrm{NaOH}$ to achieve the turn off the dye release from the graphene oxide. Final volume of the stock solution prepared by the addition of 10 $\mathrm{mL}$ of DI water was centrifuged product of BGGO. BGGO has been characterized by SEM and FT-IR. The presence of brilliant green on graphene oxide can be assured by the FTIR spectroscopy as shown in fig.1. Some of significant peaks of brilliant green have been displayed in the FTIR spectrum of BGGO with a slight shift and the peaks such as 1581, 1415, $1190 \mathrm{~cm}^{-1}$ represents $\mathrm{C}=\mathrm{C}$ stretching vibration of benzene and the aromatic $\mathrm{C}-\mathrm{N}$ stretching vibrations. These peak values indicate the assembly of brilliant green on the graphene oxide. peculiar compare to the other graphene oxide related SEM images. In the case of rhodamine B attached graphene oxide, it showed like a flower like structure, whereas the BGGO appeared like a branch of the tree. 


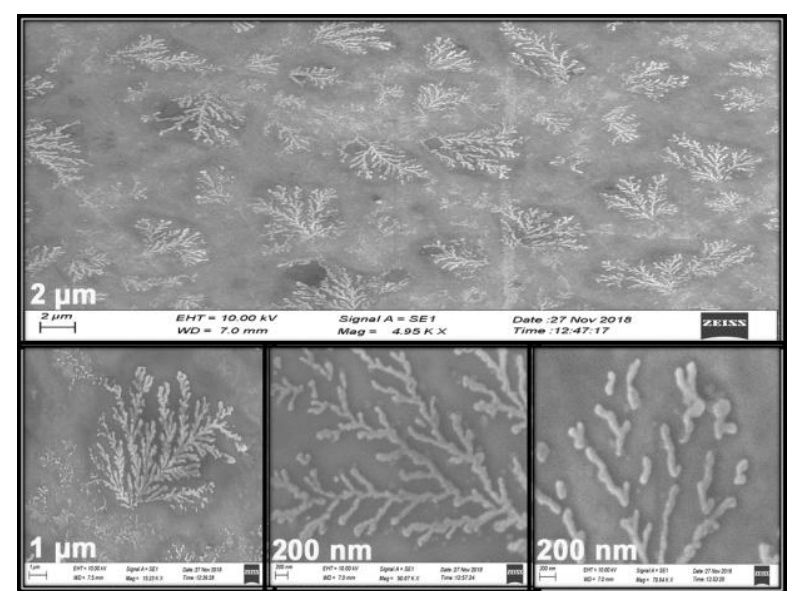

Fig 2. SEM images of BGGO under different magnification showing the dendrites like structures

Unlike the rhodamine B attached graphene oxide, the SEM image of the BGGO was quite different as shown fig. 2. The SEM of the BGGO displayed as dendrites like structure, which shown like a branches of a tree and that is very much unusual.

Next, we explored the turn on release of brilliant green sensing potential of the $\mathrm{BGGO}$ in favor of $\mathrm{CB}$ [7]. For that, we have prepared the solutions of $\mathrm{CB}$ [7] with various concentrations. We have prepared solutions of $\mathrm{CB}$ [7] in the concentration range of $10^{-2}$ to $10^{-7} \mathrm{M}$ in phosphate buffer. We prepared seven different vials with $3 \mathrm{~mL}$ volume of $\mathrm{CB}$ [7] in the range of $10^{-2}$ to $10^{-7} \mathrm{M}$ and to that $200 \mu \mathrm{L}$ of $\mathrm{BGGO}$ was added and measured the intensity of the absorbance of the released brilliant green dye. We have plotted the graph of the collected data.

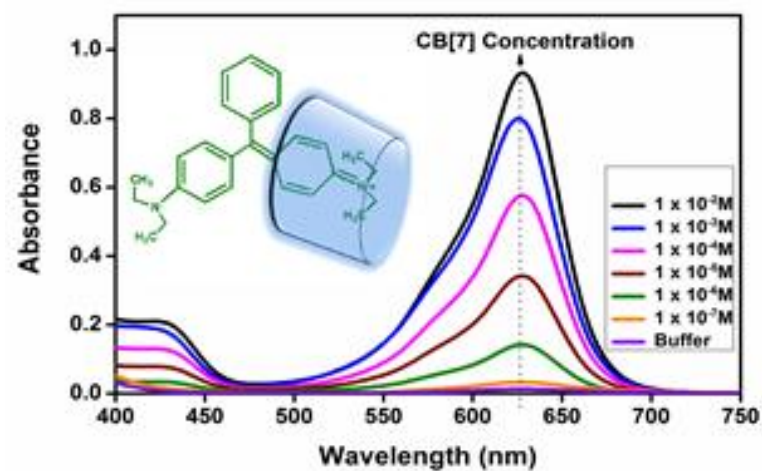

Fig 3. UV-Vis spectra of BGGO upon addition of CB[7] concentration $\left(10^{-2}\right.$ to $\left.10^{-7} \mathrm{M}\right)$.

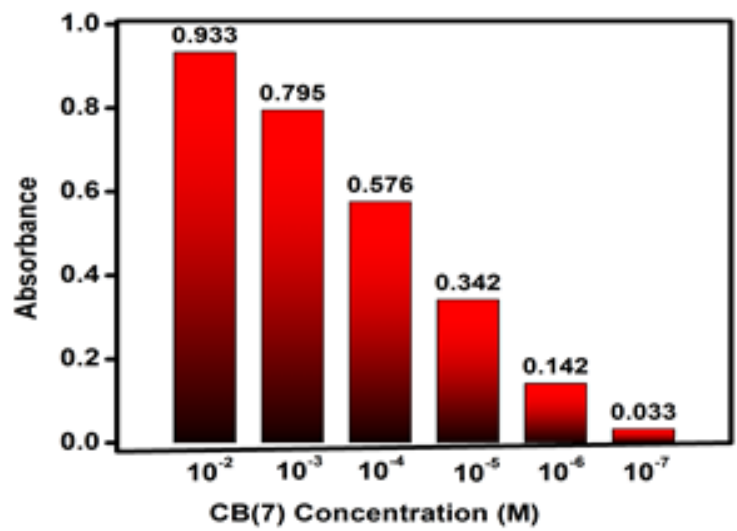

Fig 4. Quantitative increase of absorbance upon addition of $\mathrm{CB}[7]$ at various concentration.
We prepared seven different vials with $3 \mathrm{~mL}$ volume of $\mathrm{CB}$ [7] in the range of $10^{-2}$ to $10^{-7} \mathrm{M}$ and to that $200 \mu \mathrm{L}$ of BGGO was added and measured the intensity of the absorbance of the released brilliant green dye. We have plotted the graph of the collected data. As shown in fig.3. when the concentration was increased for $\mathrm{CB}$ [7], the absorbance also increased, indicating that the turn on release of brilliant green is proportional to the concentrations of $\mathrm{CB}$ [7]. From the fig. 3 and fig. 4, we could understand the relationship between the concentration of $\mathrm{CB}$ [7] with respect to the quantum of release of brilliant green and that allowed to prepare the calibration curve for the $\mathrm{CB}$ [7]. As shown in fig. 5 , the calibration curve indicated that the unknown concentration could be conveniently measured. Besides, the regression value of the slope was also supportive for the estimation of $\mathrm{CB}[7]$ of the unknown sample

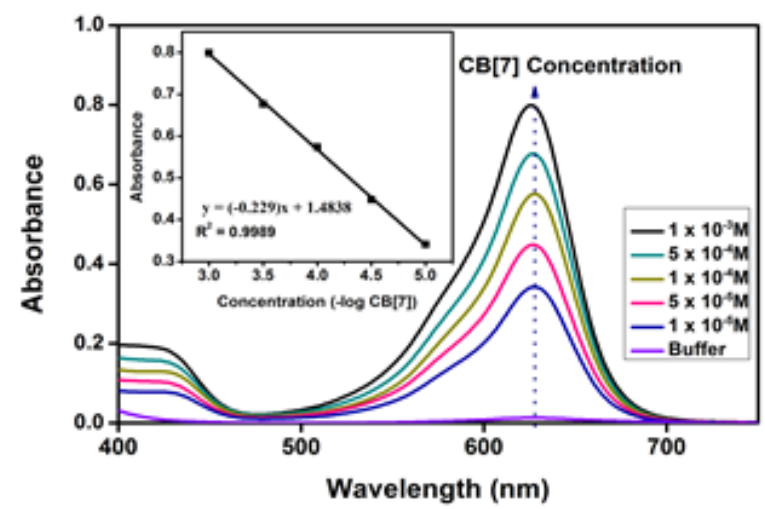

Fig 5. UV-Vis spectra of BGGO with $\mathrm{CB}[7]$ at various concentration. Inset: Concentration of $\mathrm{CB}(7)$ plotted against the absorbance of BGGO for CB[7] $\left(\lambda_{\max }=628 \mathrm{~nm}\right)$.

Based on that, we have also developed the naked eye detection of the $\mathrm{CB}$ [7] for the different concentrations As shown in fig. 6 , various concentrations of $\mathrm{CB}$ [7] could be seen, by the addition of BGGO. From that we could see the concentration of $\mathrm{CB}$ [7] in the range of $10^{-2}$ to $10^{-7} \mathrm{M}$. However, concentration of $\mathrm{CB}$ [7] in range between $10^{-2} \mathrm{M}$ to $10^{-5} \mathrm{M}$, we could visually measure the concentration without much difficulty, indicating that this method could be useful to measure concentration of $\mathrm{CB}[7]$ above $10^{-4} \mathrm{M}$ by visual method.

To understand the selectivity of this method, we prepared the solutions of $\mathrm{CB}[5], \mathrm{CB}[6]$ and $\mathrm{CB}$ [7] in phosphate buffer in the concentration of $10^{-4} \mathrm{M}$. In three different vials, $3 \mathrm{~mL}$ volume of $\mathrm{CB}[5], \mathrm{CB}[6]$ and $\mathrm{CB}[7]$ were taken and to that $200 \mu \mathrm{L}$ of BGGO was added in each vial. As shown in fig. 7 . $\mathrm{CB}$ [5] and $\mathrm{CB}[6]$ did not release the brilliant green; but $\mathrm{CB}$ [7] containing vial shown the release of brilliant green considerably, indicating the selectivity of the method, which is specific to the host molecule - $\mathrm{CB}$ [7]. Thus, this method is beneficial for the sensing of $\mathrm{CB}[7]$ and helpful to detect the concentration of $\mathrm{CB}$ [7] to the lowest of $10^{-4} \mathrm{M}$ under the visible light. This method does not require any expensive equipment to visualize the $\mathrm{CB}[7]$, which could be useful during the isolation of $\mathrm{CB}[7]$ and its derivatives 


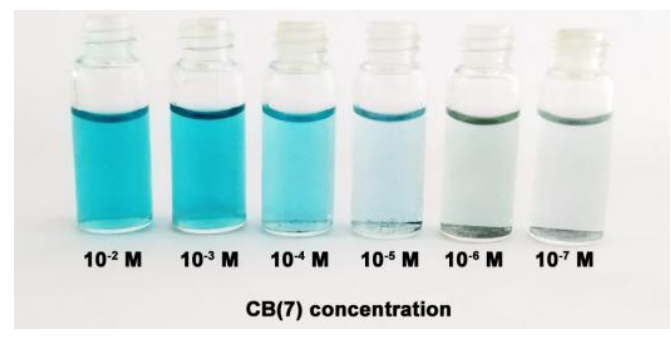

Fig 6. Naked eye detection of $\mathrm{CB}$ [7] (10-2 to 10-7 M) using BGGO under visible light.

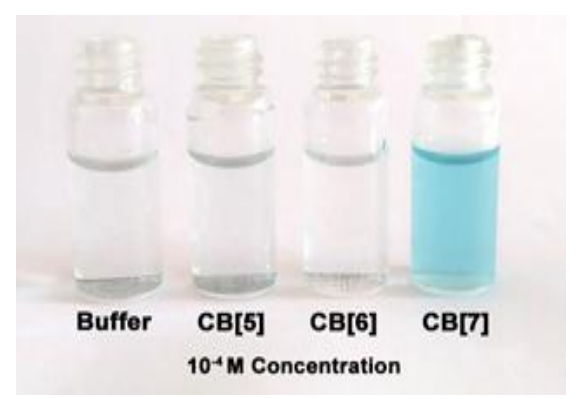

Fig 7. Selectivity of BGGO towards CB[7] by a naked eye detection method.

\section{CONCLUSION}

From the inexpensive brilliant green dye, BGGO has been synthesized, characterized and examine successfully for the detection of cucurbit[7]uril with high selectivity. The binding affinity and the water soluble property of $\mathrm{CB}$ [7] made this turn-on release of brilliant green process possible. Furthermore, BGGO has displayed high sensitivity for $\mathrm{CB}[7]$ with the maximum sensitivity of $10^{-6} \mathrm{M}$ by the UV-Visible spectroscopy. Besides, naked eye detection method provided an opportunity to detect the CB [7] with much less effort. The selectivity of $\mathrm{CB}$ [7] observed by naked eye detection will contribute the sensor for easy identification of $\mathrm{CB}$ [7] during isolation of $\mathrm{CB}$ [7] or its derivatives. Overall, the present method will provide a facile detection method for $\mathrm{CB}$ [7] in a more economical way.

\section{ACKNOWLEDGMENT}

This work is financially supported by DST- SERB, India under Early Career Research Award (ECR/2015/000318). R. $\mathrm{P}$ and $\mathrm{K}$. K thanks to KARE for offering University $\mathrm{PhD}$ fellowship. G. U. thanks to the SERB for offering Project Assistant fellowship.

\section{REFERENCES}

1. K. Kim, J. Murray, N. Selvapalam, Y. H. Ko and I. Hwang, "Cucurbiturils: Chemistry, supramolecular chemistry and applications", World Scientific. Singapore 2018, pp. 1-264

2. Z. Liu, S. K. M. Nalluri and J. F. Stoddart, "Surveying macrocyclic chemisry: from flexible crown ethers to rigid cyclophanes," Chem. Soc. Rev., vol. 46, March 2017, pp. 2459-2478,

3. A. A. Elbashir and H. Y. Aboul-Enein, "Supramolecular analytical application of Cucurbit[n] urils using fluorescence spectroscopy," Crit. Rev. Anal. Chem., vol. 45, September 2014, .pp. 52-61,

4. A. E. Rowan, J. A. A. W. Elemans and R. J. M. Nolte, "Molecular and supramolecular objects from glycoluril," Acc. Chem. Res., vol. 32, June 1999, .pp. 995-1006,

5. S. Liu, C. Ruspic, P. Mukhopadhyay, S. Chakrabarti, P. Y. Zavalij and L. Isaacs, "The cucurbit[n]uril family: Prime components for self-sorting systems," J. Am. Chem. Soc., vol. 127, October 2005, pp. 15959-15967,

6. J. Kim, I. Jung, S. Kim, E. Lee, J. Kang, S. Sakamoto et.al. "New Cucurbituril Homologues: Syntheses, isolation, characterization and X-ray crystal structures of cucurbit[n]uril $(n=5,7$, and 8)," J. Am. Chem. Soc., vol. 122, September 1999, pp. 540-541,

7. J. W. Lee, S. Samal, N. Selvapalam, H. Kim and K. Kim, "Cucurbituril homologues and derivatives: New oppurtunities in supramolecular chemistry," Acc. Chem. Res., vol. 36, February 2003, pp. 621-630,.

8. S. J. Barrow, S. Kasera, M. J. Rowland, J. Barrio and O. A. Scherman. "Cucurbiuril-based molecular recognition," Chem. Rev., vol. 115, November 2015, pp. 12320-12406,

9. H. Yin, R. Wang, "Applications of cucurbit[n]urils $(n=7$ or 8$)$ in pharmaceutical sciences and complexaion of Biomolecules" Isr. J. Chem., Vol. 57, October 2017, pp. 1-12,

10. J. M. Chinai, A. B. Taylor, L. M. Ryno, N. D. Hargreaves, C. A Morris, P. J. Hart, and A. R. Urbach, "Molecular recognition of Insulin by a synthetic receptor," J. Am. Chem. Soc. , vol. 133, April 2011, pp. 8810-8813,

11. N. Saleh, I. Ghosh, and W. M. Nau, "Cucurbiurils in drug delivery and for biomedical applicaions", Supramolecular systems in biomedical fields (Book series, RSC), vol. 13, September 2013, .pp. 164,

12. I. V. Kolesnichenko, E. V. Anslyn, " Pracical applications of supramolecular chemisry” Chem. Soc. Rev., vol. 46, January 2017, pp. 2385-2390.

13. N. G. Roman, F. M. Gregor, N. J. Wheate, and J. A. Plumb, "Cucrbit[7]uril encapsulated cisplatin overcomes resistance to cisplatin induced by rab25 overexpression in an intraperitonel ovarian cancer model" J Ovarian Res, vol. 8, December 2015, pp 62.

14. N. Dong, S.F. Xue, Q. J. Zhu, Z. Tao, Y. Zhao, and L. X. Yang, "Cucurbi[n]urils $(n=7,8)$ binding of campothecin and the effecs on solubility and reactiviy of anticancer drug" supramolecular chemisry, vol. 20, November 2008, .pp. 659-665,

15. S. Li, J. Y. W. Chan, Y. Li, D. Bardelang, W. W. Yew, and R. Wang, "Complexation of clofazimine by macrocyclic cucurbit[7]uril reduced its cardiotoxicitty without affecting antimycobaterial efficacy" Org Biomol. chem., vol.14, July 2016, pp.7563-7569

16. N. Saleh, S. Ajab, A. S ham, and S. A. Qamar, "Enhancement of in vitro fungicidal acivity of fuberidazole to botrytis cineria by cucurbiturils” J. Incl. Phenom. Macrocycl. Chem, vol.79, August 2014, pp.301-309.

17. R. Liang and X. Zhao, "Heteropore covalent organic frameworks: a new class of porous organic polymers with well-ordered hierarchical porosities," Org. Chem. Front., vol. 5, September 2018, .pp. 3341-3356,

18. H. Yin, L. Chen. B. Yang, D. Bardelang, C. Wang, S. M. Y. Lee and R. Wang, "Fluorescence enhancement and $\mathrm{pK}_{\mathrm{a}}$ shift of a rhokinase inhibitor by a synthetic receptor," Org. Biomol. Chem., vol. 15, April 2017, .pp. 4336-4343,

19. R. Prakash, G. Usha, P. Lakshminarayanan and N. Selvapalam, "Facile detecttion of cucurbit[7]uril by rhodamine B-decoraed nanoparticles," Chem. Lett., vol. 46, June 2017, .pp. 1300-1303,

20. R. Prakash, G. Usha, P. Sivaranjana, K. Karpagalakshmi, P. Lakshminarayanan and N. Selvapalam, "Graphene oxide based fluorescence sensor for cucurbit[7]uril," New J. Chem., vol. 42 June 2018, pp. 13038-13043.

21. Y. Lv, C. Tao, J. Huang, Y. Li, F. Wang, F. Cai, and J. Wang, "Self-assembly of cucurbit[7]uril on the surface of graphene/gold modified electrode: Anovel electrochemical sensing platform," Nanomaterials and Nanotechnology, vol. 6, December 2016, pp. 1-7,

22. A. Molla, Y. Li, B. Mandal, S. G. Kang, S. H. Hur, J. S. Chung, "Selective adsorption of organic dyes on graphene oxide: Theoretical and experimental analysis," Appl. Surf. Sci., vol. 464, January 2019, pp. 170-177,.

23. P. Sharma and M. R. Das, "Removal of a cationic dye from aqueous solution using graphene oxide nanosheets: Investigation of adsorption parameters," J. Chem. Eng. Data, vol. 58, December 2012, .pp. $151-158$. 


\section{AUTHORS PROFILE}

Ramesh Prakash born in Karur,Tamilnadu in 1991. $\mathrm{He}$ received his M.Phil degree from the BharathidasanUniversity, Trichy, in 2015 and obtained his MSc degree in 2014 at St. Joseph's College, Trichy. He joined Ph.D. in 2015 under the supervision of Dr. N. Selvapalam at Kalasalingam Academy of Research and Education inVirudhunagar district. He is awarded a direct-Senior Research Fellowship from CSIR in 2018 to till date. His research interest is on the area of nanomaterials synthesis and supramolecular chemistry.

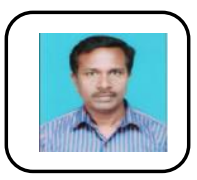

Dr. Narayanan Selvapalam received his M.S.and Ph.D. degrees from Mysore University and IIT Delhi, respectively. $\mathrm{He}$ is presently working as Associate Professor at the Kalasalingam Academy of Research and Education (Kalasalingam University) His research interests include supramolecular chemistry, glycoluril based polymers, Chemistry of cucurbiturils and cyclodextrins, organic synthesis and sensors.

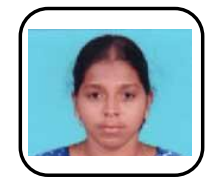

Govindaraj Usha. was born in Tirunelveli, Tamilnadu in 1991. She received her M.Phil degree from the Bharathiar university, Coimbatore, in 2015 and obtained her M. Sc. degree in 2013 at karunya University, Coimbatore. She has started her Ph. D. studies in 2016 under the supervision of Dr. N. Selvapalam at kalasalingam Academy of Research and Education, Krishnankoil, India. Her research interests are in the area of organic synthesis and supramolecular chemistry

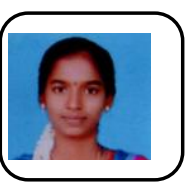

Karpagalakshmi karuppasamy. was born in sivakasi, Tamilnadu in 1993. She received her M.. Sc. degree from the Madurai Kamaraj University, Madurai, in 2016 and obtained her B. Sc degree in 2014 from, Madurai Kamaraj University, Madurai. She has started her Ph. D. studies in 2016 under the supervision of Dr. N. Selvapalam at kalasalingam academy of Research and Education, Krishnankoil, India. Her research interests are in the area of organic synthesis, nano-materials and supramolecular chemistry

Dr. Lakshminarayanan Piramuthu was born in Kizhapuliyur, Tenkasi, India, in 1979. He studied Chemistry at Sri Paramakalyani College, Alwarkurichi, India. He obtained his Ph.D. degree in the area of Development of Receptors for Recognition of Halides and Water Clusters: Further Functionalization of Receptors with Fluorophoric Units from Indian Association for the Cultivation of Science IACS, Kolkata under the direction of Professor Pradyut Ghosh. His basic focus is, to study the biologically relevant anion recognition and sensing of the synthetic receptors, he has also contributed to other areas such as crystal engineering and organic synthesis. 